\title{
Essential Competences to the Pharmacy Industry Competitivity: Case Study With Cooperators in the Town of Natal, Rio Grande do Norte, Brazil
}

\author{
Kleber Cavalcante de Sousa, Fernanda Cristina Barbosa Pereira Queiroz, Hélio Roberto Hékis, \\ Jamerson Viegas Queiróz, Marciano Furukava \\ Universidade Federal do Rio Grande do Norte, Natal, Rio Grande do Norte, Brazil
}

\begin{abstract}
The pharmaceutical industry is one of the most promising markets in the world. It is highly competitive, complex and requires huge investments in research, development, production, marketing, and sale of pharmaceutical products. One of the main strategies of the pharmaceutical industry is the promotion of its products for the medical fraternity through a drug sales representative, essential for the acceptance and prescription of your brand. This study identifies the essential drug promoter skills to competitiveness and the success of these organizations. Data were collected through semi-structured individual interviews and resulting 46 competences mentioned as the most important by own sales representatives. The research points to the need for new methods of empowerment, essential to the competitiveness of sales representatives, considering that these competences contribute to the strategies of establish industry.
\end{abstract}

Keywords: competences, competitiveness, pharmaceutical representatives, pharmaceutical industry

\section{The Pharmaceutical Industry}

The research, development, and production of drugs are fundamental to maintain health. With time the pharmaceutical industries have evolved over their role as a manufacturer of medicines to innovator, a provider of information, employer, and a significant player in the world economy (Das, 2011). Porter (2004) pointed out that, besides the global environment that businesses are located, they should worry about their competitors, suppliers, customers, substitutes, and potential entrants that influence competition in your industry generating profits.

There is an observable growth of investments in pharmaceutical laboratories in Brazil, aligned to

Kleber Cavalcante de Sousa, Master in Production Engineering, Production Engineering Department, Universidade Federal do Rio Grande do Norte.

Fernanda Cristina Barbosa Pereira Queiroz, Ph.D., Professor, Production Engineering Department, Universidade Federal do Rio Grande do Norte.

Hélio Roberto Hékis, Ph.D., Professor, Production Engineering Department, Universidade Federal do Rio Grande do Norte.

Jamerson Viegas Queiróz, Ph.D., Professor, Production Engineering Department, Universidade Federal do Rio Grande do Norte.

Marciano Furukava, Ph.D., Professor, Production Engineering Department, Universidade Federal do Rio Grande do Norte.

Correspondence concerning this article should be addressed to Jamerson Viegas Queiróz, Universidade Federal do Rio Grande do Norte, Centro de Tecnologia_Campus Universitário—-Lagoa Nova. 59078-970, Natal, Rio Grande do Norte, Brazil. E-mail: viegasqueiroz@gmail.com. 
population purchasing power, increasing the job opportunities in this category. Supporters of pharmaceutical promotions claim that marketing expenditures give innovative pharmaceutical manufacturers a fair chance to recover high R\&D expenditures (Kremer, Bijmolt, Leeflang, \& Wieringa, 2008). The pharmaceutical market is a specialized field that requires knowledge in drugs and sales skills by the sellers that sell the product to a customer (doctor) who has more scientific knowledge. It is known that the importance of competency management in this scenario is to align human resources managements with business strategy incorporating the concept of competence.

In this market, consumers do not always choose the product because it is the doctor who prescribes the medication and decides to be more appropriate to the patient. To Rubin (2003), marketing may serve as a communication channel to educate physicians and expose consumers to information that may improve their health outcomes and medical options. This is the reason to take promotional and commercial actions with the physicians and competent distributors (drugstores and wholesalers) in order to reach their planned objectives. Such spending benefits both patients and physicians in a variety of ways. The pharmaceutical representatives are valued highly by physicians as a reliable source of information. Kobayashi and Leite (2010) asserted that these professionals must be increasingly qualified and updated, so the investments could revert to keep the competitiveness of the organization.

The question refers to the importance of core competencies of the pharmaceutical representatives as competitiveness in the city of Natal, Rio Grande do Norte, Brazil, outlining the following specific objectives: to identify individual skills, classification of competencies (knowledge, skills, and attitudes), and characterization of the pharmaceutical representatives activities.

\section{Competences and Strategy}

Organizational competencies stem from the specificity of each company to identify its resources and turn them into competitive advantage. It is noteworthy that the process to transform resources into organizational competencies happens in the competitive scenario and moves the dynamic of the organizational.

This way, the strategy emerges linked to the company's competences, while its separation into personal competences goes through hierarchic levels and work teams. The effectiveness of the organization results in the ability to articulate their strategic guidance and expertise of the company, group, and individual skills. Therefore, establishing the strategic direction, aligning the organizational competences, and separating into individual competences reflect the organizational culture and the management model (Moura \& Bitencourt, 2006).

Mintzberg, Ahlstrand, Lampel, Quinn, and Ghoshal (2008) pointed out that both organizations and strategies exist independently. However, one influences the other, since strategies are constructed from a previously organizational framework, and evaluated by the strategic management at some moment. This can be conditioned, either by need to change as well as for the survival of the organization. Therefore, the strong and weak points and the opportunities and menaces must be considered as a starting point to build a new management strategy. The strategic management plays an important role in the characterization of the diverse and complex organizational processes, contributing to creating a kind of management focused on the efficiency and the search for better results (J. V. Queiroz, F. C. B. P. Queiroz, \& Hékis, 2011).

The word "competence" associated with human resource management originally appeared in a paper published by David C. McClelland in 1973 Testing for Competence Rather Than Intelligence (Daólio, 2004; 
Dutra, 2004). The concept of competence is though as a set of knowledge, abilities, and attitudes justifying a high professional performance (A. Fleury \& M. T. Fleury, 2004). To Le Boterf (2003), by embracing knowledge, skills, and attitudes, competence is something that requires a continuous motion, a constant mobilization of diverse knowledge for application to a specific situation. Hence, it can be said that to be competent, the professional needs knowledge, abilities, and attitudes which are specific to practice his/her activities. In other words, the professional must have attitudes and abilities enabling him/her to mobilize his/her knowledge, at a precise time, to reach a particular goal, in order to solve a specific problem.

For this study, we consider competence as a set of knowledge, abilities, and attitudes providing the professional and a better performance of his/her functional attributes, with efficiency in developing the activities and success. Organizations situated in competitive environments need to define its strategy and the necessary competences in a continuous learning.

\section{Individual Competences}

To Zarifian (2001), individual competences are those regarding to each professionals of the organization. These are skills that the individual possesses by his/her educational background, family creation, and his/her biography. Business competences refer to the comprehension that a person must have about the "business" of the organization and the organizational goals, as well as a comprehension of the social and political environment surrounding the organization. In this sense, a good professional must incorporate competences, or improve those already present, according to his/her experience in the environment.

A switchover between organization and persons is perceivable, both sides have effective participation in the process of professional growth. A professional unable to move his/her knowledge, information, and abilities to solve an immediately solvable conflict, becomes unproductive for reaching the organizational goals (Le Boterf, 2003). Therefore, competence refers to the professional capacity to associate all his/her personal qualities in order to get a better performance in his/her acting area.

\section{Management Competence}

Prahalad and Hamel (2004) developed the concept of essential competences in organizations. Such competences are a set of abilities and technologies resulting from contributing a fundamental difference for the competitiveness of the company. The identification and skills development are imperative for the organization to define its action strategies in a complex and ever-changing world. The companies are able to detect just a limited number of basic competences giving them strategic and sustainable advantage in the market. Competence management gains importance and is perceived as a management model derived from the resource-based theory of management.

Bitencourt (2005) pointed out that competence can be summarized and associated with the development of concepts, abilities, and attitudes. Besides, they constantly rise questioning and trigger a process of individual learning. The competences are transferred and consolidated by the relationship (interaction).

\section{Identifying Competence}

A. Fleury and M. T. Fleury (2004) highlighted the importance of competence-based management. Two models: the American Society for Training and Development (ASTD) and competency-based management were the first ones to stand out identifying the competences.

The research in skills management involves different approaches, including the views of managers, employees, and customers. The methods and techniques adopted to identify competences have the following 
features: observation of high performance employees behavior in order to delineate their qualities; application of semi-structured focused interviews; brainstorming; brain-writing; surveys; and modeling by specialists.

\section{Medical Advertisement Strategy}

Medical advertisement is defined by the World Health Organization (WHO) as all informational and persuasive activities by manufacturers and distributors to influence the prescription, supply, sale, or use of drugs (Norris, Herxheimer, Lexchin, \& Mansfield, 2007).

The industries concentrate its investments and efforts to develop drugs to treat chronic diseases that require ongoing prescriptions for longer periods (Rey, 2010). On the other hand, Palácios (2008) brought out that the use of sophisticated marketing and advertisement techniques, and the relationships established between physicians and pharmaceutical representatives are potentially harmful to the users and therefore it makes evident the importance of regulating medical advertising.

One of the main links between the pharmaceutical industry and the physicians is its sales force, the pharmaceutical representatives, or medicine advertisers, who are employed and earn their salaries working to attend the interests of their employers (Brody, 2005). In this sense, some difficulties rise from different beliefs and interest values existing among doctors, patients, and the third parties, including the media and the pharmaceutical industry (Neelam \& Jo-Ann, 2012).

The Brazilian resolution establishes a difference: For over-the-counter (OTC) medicines, advertisements can be addressed to the consumer, but for prescription drugs (either with or without retention of the prescription), the advertisement must be addressed just to professionals entitled to prescribe them, though communication channels are restricted to them. There are two different segments for pharmaceutical marketing: the market of over-the-counter medicines and the markets for strictly prescription medicines, acquisition is done through medical prescription. There is one resolution regulating the activities of pharmaceutical representatives, determining that these professionals "must be limited to scientific information and characteristics of the medicines registered by the National Health Surveillance Agency”.

The ethical matter about physicians and pharmaceutical representatives relationship has been widely discussed in the literature, evidencing a debate about conflicts between medicine users (patients) and the pharmaceutical industry, which through the pharmaceutical marketing plans a series of promotion and advertisement techniques directed to the doctors. The use of freebies, free samples, invitations to events, lunches and gifts are the central point of this debate (Fugh \& Ahari, 2007; Gagnon \& Lexchin, 2008; Palácios, 2008; Wazana, 2000).

\section{Methodology}

The study was performed based on qualitative search (semi-structured interview) with the intention to release the expression of ideas, thoughts, and opinions from the own pharmaceutical representatives. From the point of the objectives, this research is characterized as descriptive, as it intends to describe the features of a given phenomenon and to establish the relationship among variables. Sampling is non-probabilistic and the selection is made by typicality (Vergara, 2000), developing medical advertisement activities in the Natal market.

This work adopted a model praised by Dutra (2004) and A. Fleury and M. T. Fleury (2004): Competences can be surveyed based on their components of knowledge, abilities, and attitudes. The universe of the research 
was the group of pharmaceutical representatives, city of Natal, Rio Grande do Norte, Brazil. Information about functional competences was collected from 35 pharmaceutical representatives from a whole universe of 250, representing $18.8 \%$ of the professionals at state of Rio Grande do Norte, Brazil. These professionals develop their work though health professionals visits, mostly physicians of different specialties. They promote and advertise pharmaceutical products manufactured by several pharmaceutical companies.

\section{Interviews}

As a first procedure for collecting data on individual competences, a semi-structured individual interview was applied to 35 pharmaceutical representatives. For the semi-structured interview, a script was used containing: a heading indicating the date of the educational institution; identification of the post-graduate program; the name of the searcher and the title of the work related to the research; definitions of organizational and individual competence; and the question to be answered: "based on the typical activities of the pharmaceutical representatives and the competences that you consider important for the pharmaceutical representatives”.

The 35 pharmaceutical representatives were interviewed individually, in different moments and places according to their convenience. Firstly, a brief explanation was made about the reasons: What was the research about and what was it for? It was emphasized that the data provided were strictly intended for academic research.

\section{Results and Discussions}

\section{Competences Identified in the Interviews}

Forty six competences were identified in the interviews in the requirements: knowledge, abilities, and attitudes according to Table 1.

Table 1

Knowledge, Abilities, and Attitudes Detected in the Interview Session, Considering Significant Proportion

\begin{tabular}{ll}
\hline Knowledge & Importance (\%) \\
\hline Sales techniques & 77 \\
Planning techniques & 71 \\
Advertisement techniques & 66 \\
Negotiation techniques & 54 \\
Foreign language & 54 \\
Products composition & 49 \\
Informatics and internet & 43 \\
Good manners & Less than 40\% (each) \\
Human relationships, professional norms, memory techniques, notions on human health, & Importance (\%) \\
politeness, good Portuguese & 77 \\
Ability & 69 \\
\hline Good human relationships & 54 \\
Communication skills & 51 \\
Work under pressure & 51 \\
Good memory & 49 \\
Ideas synthesizing capability & 46 \\
Vecision-making capability & \\
\hline
\end{tabular}


(Table 1 continued)

\begin{tabular}{|c|c|}
\hline Ability & Importance (\%) \\
\hline \multicolumn{2}{|c|}{$\begin{array}{l}\text { Informs writing, continuous learning capability, innovation capability, creative capability, Less than } 40 \% \text { (each) } \\
\text { sense of organization, team work, integral dedication, concentration, logical reasoning }\end{array}$} \\
\hline Attitude & Importance (\%) \\
\hline Empathy & 54 \\
\hline Professional ethics & 54 \\
\hline Initiative & 54 \\
\hline Integrity & 51 \\
\hline Motivation & 49 \\
\hline \multicolumn{2}{|c|}{$\begin{array}{l}\text { Flexibility, good personal appearance, team spirit, professional position, enthusiasm, Less than } 40 \% \text { (each) } \\
\text { discipline, responsibility, commitment, dedication, good sense, patience }\end{array}$} \\
\hline
\end{tabular}

Note. Source: the authors.

Among knowledge requirements, four competences were considered relevant, cited frequency higher than $60 \%$ by the interviewed professionals. There are the knowledge requirements standing out as the most relevant:

- Sales techniques;

- Planning techniques;

- Advertisement techniques;

- Negotiation techniques.

These competences are related to the application of the daily activities knowledge of the pharmaceutical representatives, such as supplying information in an efficient and effective way to the highest number of health workers. For this, they prepare activities and promote products through advertising techniques, promotional material, freebies, and gifts, in order to gain the medical prescription, a fundamental point to increase the sales and consequently reach the planned goals of the company. The pharmaceutical companies frequently work out these competences in their trainings, providing this technical knowledge to their professionals in order to transform these individual competences into useful company competences. Other two competences identified were foreign language and product composition, which interviewed professionals believe to beessential knowledge in order to inform, negotiate, and convince the doctors to prescribe.

Among the requirements of abilities, the competences stand out with more than $60 \%$ :

- Good human relationship;

- Communication skills.

The results point toward a concern of the professionals about how to communicate and relate with the clients. The importance attached by pharmaceutical representatives to personal relationship skills and communication skills related to their daily activities are evident. Based on these data, knowing how to deal with customers is very important for the performance; as well as how to communicate in a clear concise and transparent way. Among these requirements, it is worth considering the importance perceived to the following competences: work under pressure taken as relevant in spite of receiving lower scores (less than 60\%). The ability to work under pressure is one of the new realities of the modern world, and it is very evident in the pharmaceutical market. The strong competition and high investments on research and development, beyond establish goals to be attained by their collaborators, as a way to get higher profitability.

None attitude requirement reached $60 \%$ in its score, but empathy, professional ethics and initiative got $54 \%$ and integrity reached $51 \%$, hence being the most cited competences, evidencing the preoccupation about 
professional behavior and the doctors, colleagues, and patients relationship. The ethics issue got much attention as a result of discussions, raised by researchers and experts, about the limits and acceptable conduct of pharmaceutical representatives trying to convince the physicians about a medical prescription. Another competence to stress is empathy, which is also considered as a quite relevant competence, as professionals relate empathy with a better performance of their functions.

\section{Final Considerations}

The present work detected the essential competences to pharmaceutical representatives acting in state of the Rio Grande do Norte, Brazil, by own perspective. As a whole, 46 competences were identified. These competences were classified into knowledge, abilities, and attitudes. Knowledge on sales techniques, negotiation techniques, and planning techniques is competences related with knowing how to do daily activities of medical advertisers to plan their work, to know how to negotiate, and be able to identify the needs of their clients and demonstrate the advantages and benefits of the promoted products. As evidenced by A. Fleury and M. T. Fleury (2004), knowledge competences are those related with a potential to do, and competences identified among the requirements of attitude are those showing a capability to do and denote personal habits.

Pharmaceutical representatives are professionals that transfer information about diseases and medicines, and in this case it is fundamental to have the ability to create and keep good relationships, and communicate in a clear and objective way. These relationships between physicians and pharmaceutical representatives are built through respect and ethical behavior, based on empathy and integrity (Palácios, 2008). It is necessary for the ability to create and keep good relationships, abilities to communicate in a clear and objective way, and work under pressure, in response to the high competitiveness of this market. Some attitudes are essential: empathy, professional ethics, and integrity, which are competences related to conduct and behavior, in the daily activities visiting and promoting pharmaceutical products to health professionals. It was observed that these professionals, in daily activities, carry out complex activities demanding these competences in order to reach objectives and the goals imposed by the pharmaceutical industry.

This work highlights the importance of knowledge, abilities, and attitudes for the pharmaceutical representatives in order to attain results for the pharmaceutical industry. In this sense, it is necessary to increase the investments to develop new manuals for teaching and training pharmaceutical representatives in order to turn them more capable and aligned to new realities of this market. This will make pharmaceutical representatives force more conscious about the necessary essential competences. The survey still pointed out the competences of sales techniques, good human relationships, to know how to communicate or communication skills, and work under pressure as relevant.

The competence considered as the most relevant by survey was sales techniques. This result indicates that knowledge of sales techniques is essential for the good performance of this profession, as evidenced in previous studies (Brody, 2005; Medawar, 2002; Wazana, 2000; Maguire, 1999; Norris et al., 2007). This competence is related to sales activities including: knowledge about the client's needs, about benefits and advantages of the product and being capable of keeping commercial relationships with the doctors.

Planning and negotiation techniques are competences related to knowing how to do and knowledge. Planning and negotiation are related to the daily work of the pharmaceutical representatives. Before the visits, they need to structure a plan called "pre-visits", daily and weekly schedules and the client profile. The negotiation technique, on the other hand, is necessary to go around questions and to convince doctors to 
prescribe their brand.

These results show that, besides knowing how to do, the pharmaceutical representatives must have the skills to do. In order to be able to transfer knowledge, the professionals need to read the study and retain knowledge in a constant and continuous way, and therefore, a good memory is relevant.

\section{References}

Bitencourt, C. C. (2005). Managerial competence and learning in organizations. São Leopoldo: Editora Unisinos.

Brody, H. (2005). The company we keep: Why physicians should refuse to see pharmaceutical representatives. Annals Fam Medicine, 3(1), 82-86.

Daólio, L. C. (2004). Profiles and competencies: Portrait of executives, managers and technicians. São Paulo: Érica.

Das, A. (2011). Pharmaceutical industry and the market: The case of Prozac and other Antidepressants. Asian Journal of Psychiatry, 4, 14-18.

Dutra, J. S. (2004). Skills: Concepts and tools for managing people in modern business. São Paulo: Atlas.

Fleury, A., \& Fleury, M. T. (2004). Business strategies and skills training: A puzzle kaleidoscopic Brazilian industry. São Paulo: Atlas.

Fugh, B. A., \& Ahari, S. (2007). Following the script: How drug reps make friends and influence doctors. PLoS Med., 4(4), e150.

Gagnon, M. A., \& Lexchin, J. (2008). The cost of pushing pills: A new estimate of pharmaceutical promotion expenditures in the United States. PLoS Med., 5(1), e1.

Kobayashi, R. M., \& Leite, M. M. J. (2010). Developing professional skills of nurses in service. Brazilian Journal of Nursing, 63(2), 243-249.

Kremer, S. T. M., Bijmolt, T. H. A., Leeflang, S. H. P., \& Wieringa, J. E. (2008). Generalizations on the effectiveness of pharmaceutical promotional expenditures. Journal of Advertising Research, 25, 234-246.

Le Boterf, G. (2003). Developing the competence of professionals (3rd ed.). Porto Alegre: Artmed.

Maguire, P. (1999). How direct to consumer advertising is putting the squeeze on physicians American college of physicians-American society of internal medicine observer march. Retrieved from http://www.acpinternist.org/archives/1999/03/squeeze.htm

Medawar, C. (2002). Promotion of prescription drugs: Trade tactics? Consumer Policy Review, 12, 18-30.

Mintzberg, H., Ahlstrand, B., Lampel, J., Quinn, J. B., \& Ghoshal, S. (2008). The strategy process: Concepts, contexts and cases selected. Porto Alegre: Bookman.

Moura, M. C., \& Bitencourt, C. C. (2006). The linkage between strategy and the development of managerial skills. RAE-Magazine Electronic Administration, 5(1), 1-20.

Neelam, A. V., \& Jo-Ann, M. (2012). The ethics of the medical-pharmaceutical relationship. Clinics in Dermatology, 30, 188-191.

Norris, P., Herxheimer, A., Lexchin, J., \& Mansfield, P. (2007). Drug promotion: What we know, what we have yet to learn. Geneva: World Health Organization.

Palácios, M., Rego, S., \& Lino, M. H. (2008). Promotion and advertising of medicines in teaching environments: Elements to discussion. Interface-Comunic., Saúde, Educ., 12(27), 895-908.

Porter, M. E. (2004). Competitive strategy: Techniques for analysis of industry and competition (2nd ed.). Rio de Janeiro: Campus.

Prahalad, C. K., \& Hamel, G. (2004). Competing for the future: Innovative strategies to get control of your industry and creating the markets of tomorrow. Rio de Janeiro: Campus.

Queiroz, J. V., Queiroz, F. C. B. P., \& Hékis, H. R. (2011). Strategic management and financial institutions of higher education: A case study. Iberoamerican Journal of Industrial Engineering, 3(1), 98-117.

Rey, C. G. (2010). The role of the pharmaceutical industry. Why not commercialize new antibiotics? Enferm Infecc Microbiol Clin, 28(Supl. 4), 45-49.

Rubin, P. H. (2003). The economics and impact of pharmaceutical promotion. Economic Realities in Health Care Policy, 3(1), 6-19.

Vergara, S. C. (2000). Beginning to define the methodology. São Paulo: Atlas.

Wazana, A. (2000). Physicians and the pharmaceutical industry: Is a gift ever just a gift? J. Am. Med. Assoc., 283(3), 373-380.

Zarifian, F. (2001). Objective competence: Towards a new logic. São Paulo: Atlas. 